\title{
Hortas escolares: construção de uma cultura saudável
}

\section{Nunes Vital}

Produtos processados estão cada vez mais presentes na vida das pessoas, devido à praticidade de preparo e consumo desses alimentos. Nessa perspectiva, a educação ambiental é uma alternativa para as escolas auxiliarem na construção de uma cultura alimentar saudável. A implementação de uma horta escolar, por exemplo, pode unir professores e famílias, além de proporcionar aulas mais dinâmicas e uma dieta mais equilibrada. A alimentação pobre em nutrientes está veiculada à manifestação precoce de doenças crônicas entre crianças e adolescentes, como a obesidade e o diabetes - o que produz um grande impacto na saúde pública. Nesse contexto, as hortas escolares, baseadas nos princípios da agricultura urbana e da agroecologia, podem ser orientadas de acordo com o espaço e função. Diante do exposto, este trabalho teve o objetivo de apresentar os problemas alimentares que crianças e adolescentes enfrentam e como hortas escolares influenciam positivamente na construção de uma cultura alimentar saudável. A metodologia utilizada nesse estudo foi pesquisa bibliográfica - que estabeleceu comparações entre diferentes concepções sobre a educação ambiental - e o tempo da investigação foi de quatro meses. Com as observações realizadas, ficou evidente que a horta na escola funciona como um atrativo para os alunos, possibilita a participação em um espaço fora da sala de aula e traz benefícios aos agentes envolvidos.

Palavras-chave: Escola. Educação. Família. 


\title{
School gardens: construction of a healthy culture
}

\author{
Huertos escolares: construcción de una cultura saludable
}

\begin{abstract}
Processed products are increasingly present in people's lives, due to the convenience of preparation and consumption of these foods. From this perspective, environmental education is an alternative for schools to assist in building of a healthy food culture. Implementing a school garden, for example, can bring teachers and families together, and provide more dynamic classes and a more balanced diet. Poor nutrition is linked to the early onset of chronic diseases among children and adolescents, such as obesity and diabetes - which has a major impact on public health. In this context, school gardens, based on the principles of urban agriculture and agroecology, can be oriented according to space and function. Given the above, this paper aimed to present the eating problems that children and adolescents face and how school gardens positively influence the construction of a healthy food culture. The methodology used in this study was bibliographic research - which established comparisons between different conceptions about environmental education and the research took four months. With the observations made, it was evident that the garden in the school works as an attractive tool for students allows the participation in a space outside the classroom and brings benefits to the agents involved.
\end{abstract}

Keywords: School. Education. Family.

\section{RESUMEN}

Los productos procesados se hacen cada vez más presentes en la vida de las personas, debido a la practicidad en la preparación y en el consumo de esos alimentos. En esa perspectiva, la educación ambiental es una alternativa para que las escuelas colaboren en la construcción de una cultura alimentaria saludable. La puesta en práctica de un huerto escolar, por ejemplo, pode unir profesores y familias, además de hacer que las clases sean más dinámicas y la dieta más equilibrada. La alimentación pobre en nutrientes está vinculada a la manifestación precoz de enfermedades crónicas entre niños y adolescentes, como la obesidad y la diabetes -lo que produce un gran impacto en la salud pública. En ese contexto, los huertos escolares, basados en los principios de la agricultura urbana y de la agroecología, pueden ser orientados de acuerdo con el espacio y función. Ante lo expuesto, este trabajo tuvo el objetivo de presentar los problemas alimentarios que niños y adolescentes enfrentan y demostrar cómo los huertos escolares ejercen influencia positiva en la construcción de una cultura de alimentación saludable. La metodología utilizada en ese estudio fue la investigación bibliográfica -que estableció comparaciones entre diferentes concepciones sobre la educación ambiental. El tiempo de la investigación fue de cuatro meses. Con las observaciones realizadas, quedó evidente que colaborar en el huerto en la escuela es atractivo para los alumnos, permite la participación en un espacio fuera del aula y trae beneficios a los participantes.

Palabras-clave: Escuela. Educación. Familia.

\section{INTRODUÇÃO}

A sociedade contemporânea, marcada pela evolução industrial, cada vez mais tem inserido na vida das pessoas produtos industrializados, congelados e enlatados. Em um mundo caótico, torna-se irresistível ceder a esse padrão alimentar, devido à praticidade e rapidez de preparo desses alimentos. 
Para toda e qualquer sociedade o esforço para uma melhor qualidade alimentar se faz necessário para uma melhor qualidade de vida, no entanto, não é uma obrigação só da família ou da escola, mas sim um trabalho em conjunto.

Nessa perspectiva a educação ambiental surge como uma necessidade das sociedades contemporâneas, uma vez que as questões socioambientais têm sido cada vez mais discutidas e abordadas pelos vários segmentos da sociedade, em decorrência da gravidade da degradação do meio natural e social, (WOJCIECHOWSKI 2006).

De acordo com Pessa (2008), é principalmente na infância que os hábitos alimentares são formados, isso mostra a necessidade de um trabalho que colabore com uma sociedade mais saudável.

Alguns agentes atuam como influenciadores na construção de uma cultura alimentar, estão entre eles a família, fundamental na transmissão de conhecimentos. Contudo, com as demandas do dia a dia, hábitos como reunir-se para as principais refeições diárias tem sido cada vez mais escasso. A mídia televisiva e as redes sociais procuram determinar escolhas alimentares com suas propagandas apetitosas, ao visar unicamente a questão financeira; assim, a escola, deve influenciar de forma positiva seus alunos, trabalhando educação e saúde de forma a melhorar a qualidade de vida.

Fetter e Muller (2008), apontam que as crianças e adolescentes das cidades estão sempre em frente a vídeo games, computadores e televisores, sem muito contato com a natureza, por isso professores devem resgatar este contato. É desta forma que as hortas nas escolas possuem um papel importantíssimo, pois proporcionam uma reflexão sobre a importância de uma alimentação saudável e equilibrada.

Segundo Toral (2009), as práticas alimentares adotadas na infância têm correspondido a dietas ricas em gorduras, açúcares e sódio, com poucas porções de frutas e hortaliças. Este quadro está relacionado à manifestação cada vez mais precoce de doenças crônicas entre os adolescentes, como a obesidade e o diabetes, o que envolve um grande impacto em saúde pública. Nesse sentido, é fortemente estimulado o desenvolvimento de estratégias de intervenção nutricional, inseridas no campo da educação em saúde, como uma perspectiva para o controle do problema nessa fase da vida.

Nesse contexto, este trabalho evidencia os problemas alimentares que as crianças enfrentam e como a implementação de hortas escolares impacta positivamente na 
construção de hábitos alimentares saudáveis. Para alcançar tal objetivo, analisou-se as concepções de vários autores sobre educação ambiental associadas à uma breve análise dos principais problemas relacionados à uma alimentação insatisfatória como: obesidade, desnutrição e fome; além disso, investigou-se como a merenda escolar e os profissionais que atuam nessa área influenciam na cultura alimentar do aluno.

\section{OBESIDADE}

A obesidade é definida, de forma geral, como uma doença que apresenta um acúmulo excessivo de gordura no corpo, sendo consequência de balanço energético positivo, que acarreta repercussões à saúde com perda importante não só na qualidade como na quantidade de vida (MENDONÇA \& DOS ANJOS, 2004)

Segundo PIZZATTO (1992), o estudo da obesidade pode parecer irrelevante em um país em crise financeira. No entanto, a obesidade tem uma incidência cada vez mais elevada. Esse fato ocorre tanto entre as classes sociais menos favorecidas economicamente, como nas mais abastadas- não apenas no Brasil, mas em inúmeros países.

Atualmente a obesidade é uma condição agravante nas sociedades modernas devido ao seu avanço em diferentes partes do planeta. No Brasil fatores como o aumento do poder aquisitivo da população, maior acesso aos programas de saúde e a diminuição da taxa de fertilidade têm contribuído para um considerável aumento no número de pessoas obesas, principalmente crianças. Observa-se que em todas as regiões brasileiras a distribuição do excesso de peso é ligeiramente mais elevada na área urbana do que na área rural do país (COITINHO et al., 1991; MONTEIRO et al., 2000).

De acordo com a Organização Mundial da Saúde (OMS), em 2005 haviam cerca de 1,6 bilhões de adultos no mundo ( 15 anos ou mais de idade) apresentando excesso de peso, e, pelo menos, 400 milhões apresentavam obesidade. Projeções da OMS já estimavam que, em 2015, aproximadamente 2,3 bilhões de adultos estariam em condição de excesso de peso e mais de 700 milhões obesos.

No Brasil existe uma política nacional de alimentação (PNAN), aprovada em junho de 1999 pela Portaria $n^{\circ}$ 710, de 10 de junho de 1999, que declara o compromisso do Ministério da Saúde com a erradicação dos males relacionados à alimentação como: 
pobreza, desnutrição infantil e materna, e também obesidade na população adulta. A proposta dessa política é assegurar o direito à uma alimentação de qualidade como também o combate aos distúrbios causados pela ausência ou mau uso dos alimentos disponíveis (COUTINHO et al 2009).

No Brasil tem se detectado um alto índice de obesidade, de acordo com a ABESO (Associação Brasileira para o Estudo da Obesidade e da Síndrome Metabólica), com 50\% da população acima do peso, ou seja, na faixa de sobrepeso e obesidade. Entre crianças, o índice estaria em torno de 15\%. A obesidade é caracterizada pelo acúmulo excessivo de gordura corporal, ocasionada em grande parte por um desequilíbrio crônico traduzido pelo aporte calórico maior que a demanda metabólica. Seu diagnóstico é realizado por meio da quantificação da proporção da gordura armazenada no corpo em relação aos demais tecidos. (BURGOS et al 2010).

Portanto, cabe salientar a importância de uma alimentação saudável como forma de evitar doenças ocasionadas pela falta de nutrientes e prevenir outras como hipertensão, diabetes, câncer e problemas do coração. Triches \& Giugliani (2005) apontam que os padrões alimentares mudaram, explicando em parte o contínuo aumento da adiposidade nas crianças como o pouco consumo de frutas, hortaliças e leite, o aumento no consumo de guloseimas (bolachas recheadas, salgadinhos, doces) e refrigerantes, bem como a omissão do café da manhã.

Diante tal situação os ambientes escolares juntamente com o trabalho do professor podem ser determinantes para traçar estratégias para o controle da obesidade, como também para a introdução de conceitos em educação e saúde.

\section{DESNUTRIÇÃO E FOME}

Dados da Food and Agriculture Organization das Nações Unidas já estimavam no ano de 2009 que 963 milhões de pessoas passavam fome no mundo, das quais 1/3 eram crianças, normalmente acometidos da forma mais letal de má nutrição, desnutrição energético-proteica (DEP).

Para Salas Martins (2007), a nutrição e o crescimento estão intrinsecamente associados; se as crianças não tiverem suas necessidades nutricionais básicas atendidas, 
elas não atingem seus potenciais genéticos de crescimento, o que acarreta déficits estaturais para suas idades.

De acordo com Monteiro (2003), a desnutrição ou deficiência nutricional é uma doença que decorre do aporte alimentar insuficiente em energia e nutrientes ou ainda, com alguma frequência, do inadequado aproveitamento biológico dos alimentos ingeridos geralmente motivado pela presença de doenças, em particular doenças infecciosas. Cabe ainda ressaltar a diferença entre fome e desnutrição, e isso ficará possivelmente mais claro por meio de um exemplo. Um indivíduo pode ser pobre sem que essa condição ocasione um estado de fome, bastando que sua condição de pobreza se expresse por carências básicas não ligadas à alimentação, geralmente relacionados a bens de consumo.

Para Silveira et al (2010), apesar da prevalência de desnutrição ter diminuído no Brasil, principalmente no Nordeste, observa-se que, devido às diferenças sociais, tal agravo ainda continua a ser um relevante problema de saúde pública, especialmente em alguns bolsões de pobreza localizados nas periferias das grandes cidades.

Não se pode falar em um único fator causal, mas sim em uma série de fatores, entre eles as políticas públicas de combate à pobreza, a atuação mais direta dos profissionais de saúde e também os profissionais da educação, atuando como agentes modificadores da sociedade.

Para Collares (1992), dentre os inúmeros fatores correlacionados com o fracasso escolar, aparecem tanto os extraescolares como os intraescolares. Os extraescolares dizem respeito às más condições de vida e subsistência de grande parte da população escolar brasileira. Assim, as péssimas condições econômicas, são responsáveis dentre outros fatores pela fome e desnutrição.

Estudos indicam que unicamente nos casos de desnutrição grave ocorrem alterações no sistema nervoso central (responsável pelas funções intelectuais dos indivíduos) o que reflete diretamente na anatomia do cérebro (redução do peso, do tamanho, do volume, do número de células, da quantidade de mielina etc.). Mas essas alterações anatômicas não permitem nenhuma conclusão sobre os seus efeitos no funcionamento cerebral (DOBBING, 1972). Diante essa constatação entanto, não se deve impedir que se fechassem os olhos por muito tempo para o estudo das causas intraescolares na produção das dificuldades de escolarização dessas crianças. A desnutrição pode ser entendida como processo produtor de dificuldades para 
aprendizagem do aluno, porém, cabem ainda reflexões sobre sua ação direta no processo educacional.

\section{MERENDA ESCOLAR}

A alimentação é um ato, não apenas fisiológico, mas, também, de integração social e, portanto, é fortemente influenciada pelas experiências que as crianças são submetidas e os exemplos em seu círculo de convivência (ACCIOLY,2009).

No ano de 2009 foi sancionada a lei 11947/09, aprovando a distribuição de merenda escolar para todos os alunos da rede pública (FIOROTTI, 2011).

O Brasil se destaca como um dos países com maior experiência em alimentação escolar. O Programa Nacional de Alimentação Escolar do Brasil é o mais antigo programa social do Governo federal, na área de educação; vem sendo desenvolvido desde 1954, quando era responsabilidade da Comissão Nacional de Alimentos e tinha como objetivo atender aos estudantes carentes do Nordeste do país, por meio da distribuição de leite em pó (FIGUEROA \& LUCENA, 2006).

Nunes (2000), aponta o trabalho das merendeiras -profissionais envolvidas diretamente no preparo e distribuição da alimentação escolar- e o papel que desempenham na educação. Esse papel não se limita à preparação de alimentos e à higienização de áreas físicas; elas têm sensibilidade para outras questões e possuem um conhecimento de ordem prática, que deveria ser reconhecido na formação de comportamentos relativos à ética e à convivência social. O trabalho dessas profissionais é socialmente desvalorizado por não exigir alto nível de escolaridade e qualificação.

Para Fernandes (2006), a escola é um espaço social onde os alunos passam grande parte do seu tempo; eles convivem, aprendem e produzem, portanto, torna-se um ambiente favorável para o desenvolvimento de ações que visam a promoção da saúde. A escola também influencia na formação de hábitos alimentares saudáveis, atingindo os estudantes nas etapas mais influenciáveis da sua vida, seja na infância ou na adolescência. Contudo, se há ausência de um nutricionista no espaço escolar, a proposta de construção de uma cultura saudável é dificultada.

É importante reconhecer que a alimentação é uma parte fundamental da cultura de um indivíduo; deve-se levar em conta as práticas, costumes e tradições exigindo algumas 
medidas que possibilitem manter, adaptar ou fortalecer a diversidade e hábitos saudáveis de consumo e de preparação de alimentos, garantindo que as mudanças na disponibilidade e acesso aos alimentos não afete negativamente a composição da dieta e do consumo alimentar (GOMES, 2017).

A alimentação escolar deve ser considerada como "uma refeição oferecida pela escola para manter a criança alimentada durante a jornada escolar diária, independentemente de suas condições socioeconômicas, e não como instrumento para erradicar a desnutrição, a fome e o fracasso escolar”.

\section{HORTAS ESCOLARES}

O homem vem tirando da terra seu sustento desde os primórdios; assim, aprendeu a prepará-la para o cultivo e passou a ter uma relação homem-natureza, já que depende dela para a sua sobrevivência (FIOROTTI, 2011). No entanto, para muitos seres humanos esta relação está se perdendo ao longo do tempo, para a maioria o solo de onde o seu alimento é tirado é simplesmente terra, pois, atualmente na sua rotina não há mais tempo para tal relação, (FRISK, 2008).

A promoção da saúde leva a refletir sobre a mesma. Sem ter a pretensão de finalizar esta discussão, propomos que saúde é um conceito em construção, em movimento, dependendo de valores sociais, culturais, subjetivos e históricos (BRASIL, 2002). Nesse sentido, trabalhar o tema alimentação na escola faz-se necessário, contribuindo para a construção social e cultural do aluno, além de promover saúde.

De acordo com o programa Nacional de Alimentação Escolar (PNAE) implantado em 1995, toda escola deve ter um cardápio nutritivo, para proporcionar que todas as crianças tenham hábitos alimentares adequados com a sua idade e necessidade energética. Essa proposta sugere, que dessa forma, se inicie uma política de hábitos alimentares saudáveis, para que desde pequenos, os alunos conheçam a importância de se alimentar de forma natural e saudável.

Para o Ministério da Saúde, Brasil (2016) a escola é um local privilegiado para a promoção da saúde e prevenção do sobrepeso e da obesidade. Algumas ações realizadas no ambiente escolar contribuem para formação de hábitos alimentares saudáveis e facilitam o consumo desses alimentos pelas crianças e adolescentes. Por exemplo: a 
substituição da comercialização nas cantinas escolares de alimentos considerados não saudáveis por preparações mais saudáveis; a oferta de frutas e hortaliças na alimentação escolar e nas cantinas comerciais; a restrição às propagandas de alimentos com quantidades elevadas de açúcares, gorduras saturadas, trans. e sódio.

De acordo com essas informações, a Organização Mundial de Saúde recomenda investimentos no desenvolvimento de hábitos alimentares saudáveis em crianças e adolescentes, o que influencia na qualidade de vida dos mesmos.

No Brasil a educação ambiental foi regulamentada pela Política Nacional de Educação Ambiental (PNEA), instituída pela Lei 9.795, de 27 de abril de 1999, que estabelece e define seus princípios básicos, incorporando oficialmente a Educação Ambiental nos sistemas de ensino. Dessa forma, os professores têm a responsabilidade de instruir seus alunos para que mudem seus hábitos alimentares e fiquem cientes das consequências que uma má alimentação pode provocar no seu desenvolvimento físico e intelectual, e ao mesmo tempo conscientizá-los dos benefícios de uma alimentação saudável e a construção de uma horta no ambiente escolar.

A proposta para o ensino básico tradicional é incorporar esses conhecimentos ao currículo, porém isso não é uma tarefa tão fácil como se imagina; são muitas as barreiras que precisam ser quebradas para que a educação ambiental de fato comece a dar os resultados esperados. Ademais, a educação ambiental e a educação em saúde ainda continuam a ser consideradas responsabilidade dos professores de ciências, que não podem carregar toda essa incumbência sozinhos (GRYNSZPAN, 1999).

O tema ambiental é uma das principais preocupações da sociedade moderna e provoca em todos os setores uma grande apreensão. Assim, há uma série de iniciativas no sentido de reverter as consequências danosas à vida na terra. Uma dessas iniciativas é a Educação Ambiental. Apesar de enfrentar grandes barreiras, a EA vem sendo implementada em instituições de educação na busca da formação de cidadãos conscientes, comprometidos e interessados com os principais problemas da sociedade (SERRANO, 2003).

Alguns fatores dificultam a introdução desses conceitos na educação atual, tais como o tamanho da escola, o alto número de alunos para poucos professores, além da predisposição destes professores em passar por um processo de treinamento; falta também incentivos para a direção realmente implementar um projeto ambiental, pois há 
um receio que essa implementação irá alterar a rotina da escola e Ihes colocar responsabilidades sem um adicional no salário.

Nessa perspectiva de importância da educação ambiental, as hortas escolares embasadas nos princípios da agricultura urbana e da agroecologia podem ser orientadas em função do espaço e função, contribuindo para o resgate da relação ser humano ambiente natural - alimento. Essa ligação permite a elaboração de arcabouços científicos, pedagógicos e didáticos, consistentes e com possibilidades de aplicação em escolas urbanas e rurais para o alcance dos objetivos fundamentais da educação alimentar e nutricional contribuindo para formação de uma cultura saudável. (MACHADO e MACHADO, 2002).

O processo de urbanização avançou ao longo dos anos e talvez esse seja o motivo pelo qual o interesse pela produção agrícola cada vez mais tenha sido perdido. No Brasil as práticas agrícolas já estiveram legalmente inseridas no currículo do Ensino fundamental, com objetivos voltados para a preparação de mão-de-obra para atuação no meio considerado rural (BRASIL, 1971).

A horta inserida no ambiente escolar pode ser um laboratório vivo possibilitando o desenvolvimento de diversas atividades pedagógicas em educação ambiental e alimentar unindo teoria e prática de forma multidisciplinar, auxiliando no processo de ensinoaprendizagem e estreitando relações através da promoção do trabalho coletivo e cooperado entre os agentes sociais envolvidos (MORGADO, 2008).

O plantio de hortas e jardins torna a escola mais agradável permitindo transformar o espaço físico árido em espaço verde. Particularmente, as hortas permitem aos alunos e à comunidade escolar vivenciarem os ciclos vitais da natureza, o cuidado com os seres vivos, e atentarem para a importância de uma alimentação saudável. (IARED et al 2011).

Além de proporcionar a construção de uma cultura alimentar, na impossibilidade de realizar uma aula de campo fora do ambiente escolar, a horta inserida na escolar pode ser um laboratório vivo que possibilita o desenvolvimento de diversas atividades pedagógicas em educação ambiental e alimentar unindo teoria e prática de forma contextualizada, auxiliando no processo de ensino-aprendizagem e estreitando relações através da promoção do trabalho coletivo e cooperado entre os agentes sociais envolvidos, (MORGADO, 2008). 
A construção coletiva das hortas escolares, além dos benefícios da prática da agricultura urbana, ao propiciar o envolvimento das crianças na preparação do terreno, no plantio, nos cuidados com a planta, na colheita e na participação na preparação das refeições, (MUNIZ et al 2007).

De acordo com o relato de Turano (1990) o conhecimento e a ação participativa na produção e no consumo principalmente de hortaliças - fonte de vitaminas, sais minerais e fibras - despertam nos alunos mudanças em seu comportamento alimentar, atingindo toda a família.

Uma questão que pode servir de argumento para justificar a não instalação de hortas nos ambientes escolares pode ser a carência de espaço físico, porém, essa situação pode ser resolvida com várias técnicas de aproveitamento de espaço. As hortas verticais feitas com garrafas pet podem ser alternativas viáveis para solucionar o problema de espaço, além disso possibilita também conceitos em educação ambiental referentes a reciclagem.

\section{METODOLOGIA}

A metodologia utilizada nesse estudo consistiu de uma pesquisa bibliográfica realizada através de comparações entre concepções de diferentes autores sobre a educação ambiental com o objetivo de compreender como a introdução das hortas escolares contribuem para a formação da comunidade escolar, também como esse conhecimento pode ser usado na sociedade em geral. O critério utilizado para a escolha dos artigos foi a relação com o tema apresentado, considerando os anos de publicação de 1971 a 2016. A análise feita foi de caráter qualitativo, todos os dados numéricos mencionados neste trabalho foram colhidos prontos em artigos e sites institucionais.

\section{CONSIDERAÇÕES FINAIS}

A implantação de hortas escolares abordada nesta pesquisa permite a compreensão do papel da escola a ser exercida em parceria com a família dos alunos, uma vez que as pessoas recebem influencias de diversos meios contribuindo para construção de sua cultura alimentar. 
Fica visível que com o aumento e desenvolvimento da produção de comidas rápidas e com pouco valor nutricional, cada vez mais temos pessoas obesas e com problemas de saúde, fato este que tem causado grande preocupação para os órgãos governamentais.

A fome e a desnutrição em todos os seus níveis, se apresentam como agravantes na vida dos alunos, que por vezes tem como única refeição do dia a que recebe na escola. As influências dessas condições no aprendizado ainda são bastante discutidas, mas o que se percebe é que uma criança com fome não produz o que deveria no ambiente escolar. A desnutrição é também um problema social que requer ações do sistema público.

A merenda escolar é uma refeição valiosa para os alunos, porém, na maioria das vezes é feita sem nenhum acompanhamento técnico, o que pode comprometer sua proposta de uso, cabe salientar que não é um instrumento de erradicação da desnutrição, nessa perspectiva é importante lembrar que a valorização das merendeiras e o maior apoio das escolas podem influenciar na construção de uma cultura alimentar saudável.

As investigações apontam o potencial das atividades agrícolas no que diz respeito a construção de hortas, a educação alimentar e para o desenvolvimento do aluno como ser pensante e formador da sociedade.

A horta inserida na escola funciona como um atrativo para os alunos, possibilitando a participação em um espaço fora da sala de aula, porém é necessária a participação de toda comunidade escolar tendo em vista que todos os setores são beneficiados.

É notória a necessidade de que no ambiente escolar sejam trabalhadas formas de integralizar o trabalho dos alunos a partir de atividades que despertem o interesse dos mesmos, fazendo com que a estadia na escola não seja vista como algo chato e enfadonho, mas isso só é passível a partir do momento que a educação ambiental ganha espaço, nem todas as escolas estão dispostas a encarar um projeto dessa natureza, talvez pautados na argumentação da desvalorização do ensino e da profissão. O que se sabe na realidade e este trabalho deixou bem claro é que a introdução dessas práticas na escola possibilita com que o ambiente seja mais harmonioso e que os alunos estejam mais interessados nas aulas, com isso melhore o trabalho do professor.

O que não pode ser deixado de fora é o benefício que tudo isso traz para saúde, uma vez que os hábitos alimentares da sociedade contemporânea favorecem a obesidade e também o aparecimento de várias doenças. 
Diante de todas as abordagens feitas no decorrer desse trabalho fica claro que a sociedade contemporânea precisa de uma reeducação alimentar, isso é facilitado com o estreitamento das relações entre familiares e a escola na busca de meios que contribuam na formação dos alunos.

Portanto, julgamos positiva a introdução de hortas nas escolas como agentes transformadores do ambiente escolar sendo uma forma de construção de uma cultura alimentar saudável.

\section{REFERÊNCIAS}

Associação Brasileira para o estudo da Obesidade e da Síndrome metabólica- Mapa da Obesidade. Disponível em: <http://www.abeso.org.br/atitude-saudavel/mapa-obesidade> Acesso em 20 de dez. 2016

ACCIOLY, Elizabeth. A escola como promotora da alimentação saudável. Ciência em tela, Rio de, 2009.

BRASIL. Lei no 9.795, de 27 de abril de 1999. Dispõe sobre a educação ambiental, institui a Política Nacional de Educação Ambiental e dá outras providências. Diário Oficial [da] República Federativa do Brasil, Brasília, DF, no 79, Seção 1, p.1-3, 28 abr. 1999.

BRASIL. Ministério da Saúde, Secretaria de Políticas de Saúde. Promoção da Saúde. Brasília, DF, $1999-2002$.

BRASIL. Lei de Diretrizes e Bases para a Educação Nacional - LDBEN. Lei nº 5.692, de 11 de agosto de 1971.

BURGOS, Miria Suzana et al. Uma análise entre índices pressóricos, obesidade e capacidade cardiorrespiratória em escolares. Arq Bras Cardiol, v. 94, n. 6, p. 739-44, 2010.

COLLARES, Cecilia Azevedo Lima. Ajudando a desmistificar o fracasso escolar. São Paulo: FDE, 1992.

COUTINHO, Janine Giuberti et al. A organização da Vigilância Alimentar e Nutricional no Sistema Único de Saúde: histórico e desafios atuais. 2009.

COITINHO, Denise Costa et al. Condições nutricionais da população brasileira: adultos e idosos: Pesquisa Nacional sobre Saúde e Nutrição. In: Condições nutricionais da população brasileira: adultos e idosos: Pesquisa Nacional sobre Saúde e Nutrição. INAN, 1991.

DOBBING, J. Nutrition, the nervous system and behavior. OPaS, n.251, 1972. 
FAO (Organización de las Naciones Unidas para la Agricultura y la Alimentación). Mapa de la desnutrición: un proceso en curso. Santiago: La Organización; 2009.

FERNANDES, F. M. Alimentação e nutrição entre escolares: caso dos alunos de uma escola do município, Vitória -ES. 2006. 49 f. Monografia (Especialização em Nutrição Clínica) Curso de Pós-Graduação em Nutrição Clínica, Universidade Veiga de Almeida, Vitória, 2006. Disponível em: Acesso em: 10 de julho de 2017

FETTER, I. S; MULLER, J; Agroecologia Merenda Escolar e Ervam Medicinais Resgatando Valores no Ambiente escolar. 2008. Disponível em:< http://www6.ufrgs.br/seeragroecologia/ojs/sitemap. php> Acesso em 20 de dez. 2016.

FIGUEROA PEDRAZA, Dixis; LUCENA SOUSA DE ANDRADE, Sonia Lúcia. A alimentação escolar analisada no contexto de um programa de alimentação e nutrição. Revista Brasileira em Promoção da Saúde, v. 19, n. 3, 2006.

FIGUEROA PEDRAZA, Dixis et al. Avaliação do programa de alimentação escolar municipal de Olinda-Pernambuco. Revista Brasileira em Promoção da Saúde, v. 20, n. 2, 2007.

FIOROTTI, Josiana Laporti et al. Horta: a importância no desenvolvimento escolar. Anais... XIV Encontro Latino-Americano de Iniciação Científica. Universidade Vale do Paraíba, 2011.

FNDE. Programa Nacional de Alimentação Escolar (Pnae). Disponível em: <http://www.fnde.gov.br/programas/alimentacao-escolar/alimentacao-escolar apresentação> Acesso em 21 de dez. 2016

FRISK, P. R; Horta na Escola; Publicado, 2008. Disponível em: <http://www.guiadeitupeva.com.br/noticias/ver. php?cit=18> Acesso em 14 de junho. 2017.

GOMES, Wedna da Silva Teixeira. Alimentação escolar saudável. 2017.

GRYNSZPAN, D. Educação em saúde e educação ambiental: uma experiência integradora. Cad. Saúde Pública, 1999, vol.15 supl.2, p.133-138.

IARED, Valéria Ghisloti et al. Hortas escolares: desafios e potencialidades de uma atividade de Educação Ambiental. Educação Ambiental em Ação, n. 36, 2011.

MACHADO, A. T. e MACHADO, C. T. de T. Agricultura Urbana. Documentos. Planaltina, DF: Embrapa Cerrados, 2002.

MENDONÇA, Cristina Pinheiro; DOS ANJOS, Luiz Antonio. Aspectos das práticas alimentares e da atividade física como determinantes do crescimento do sobrepeso/obesidade no Brasil Dietary and physical activity factors as determinants of the increase. Cad Saúde Pública, v. 20, n. 3, p. 698-709, 2004. 
MORGADO, F; S, A Horta Escolar na Educação Ambiental e Alimentar: Experiência do Projeto Horta Viva nas Escolas Municipais de Florianópolis, 2008. Disponível em: http://www.extensio.ufsc.br/20081/A-horta- escolar.pdf> Acesso em 23 de jun 2010.

MONTEIRO, C. A.; CONDE, W. L. - Evolução da obesidade nos anos 90: a trajetória da enfermidade segundo estratos sociais no nordeste e sudeste do Brasil. In: MONTEIRO, C. A. (ed. lit.) - Velhos e novos males da saúde no Brasil: a evolução do país e suas doenças.São Paulo: Universidade de São Paulo, 2000. 421-431

MONTEIRO, Carlos Augusto. A dimensão da pobreza, da desnutrição e da fome no Brasil. Estudos avançados, v. 17, n. 48, p. 7-20, 2003.

Ministério da Saúde - Política Nacional de Alimentação e Nutrição, 2016. Disponível em: <http://bvsms.saude.gov.br/bvs/publicacoes/pnan.pdf> Acesso em 01 de jan. 2017

MUNIZ, V. M.; CARVALHO, A.T. Programa Nacional de Alimentação Escolar em município do estado da Paraíba: em estudo sob o olhar dos beneficiários do Programa. Rev. Nut., Campinas, maio/jun. 2007.

NUNES, B.O. O sentido do trabalho para merendeiras e serventes em situação de readaptação nas escolas públicas do Rio de Janeiro. 2000. Dissertação (Mestrado) -Escola Nacional de Saúde Pública, Fundação Oswaldo Cruz, Rio de Janeiro. 2000.

PESSA, R.P. Seleção de uma alimentação adequada. In: DUTRA-DE-OLIVEIRA, J.E.MARCHINI, J.S. Ciências nutricionais. São Paulo, Sarvier, 2008. p.21-51

PIZZATTO, V.T. Obesidade infantil. 76ª edição. São Paulo: Savier, 1992.

SALAS MARTINS, Ignez et al. Pobreza, desnutrição e obesidade: inter-relação de estados nutricionais de indivíduos de uma mesma família. Ciência \& Saúde Coletiva, v. 12, n. 6, 2007.

SILVEIRA, Kátia BR et al. Associação entre desnutrição em crianças moradoras de favelas, estado nutricional materno e fatores socioambientais. Jornal de Pediatria, v. 86, n. 3, 2010.

SERRANO, C. M. L. Educação ambiental e consumerismo em unidades de ensino fundamental de Viçosa-MG. Dissertação (mestrado em Ciência Florestal) - Universidade Federal de Viçosa: UFV, 2003. 91p. Disponível em: http://www.ipef.br/servicos/teses/arquivos/serrano,cml.pdf. Acesso em: 01 jul 2017.

TORAL, Natacha et al. A alimentação saudável na ótica dos adolescentes: percepções e barreiras à sua implementação e características esperadas em materiais educativos. Cadernos de Saúde Pública, v. 25, n. 11, p. 2386-2394, 2009.

TRICHES, Rozane Márcia et al. Obesidade, práticas alimentares e conhecimentos de nutrição em escolares. Rev Saúde Pública, v. 39, n. 4, p. 541-7, 2005.

TURANO, W. A didática na educação nutricional. In: GOUVEIA, E. Nutrição Saúde e Comunidade. São Paulo: Revinter, 1990. 246 p. 
WOJCIECHOWSKI, T. (2006). Projetos de Educação Ambiental no Primeiro e no Segundo Ciclo do Ensino Fundamental: Problemas Socioambientais no Entorno de Escolas Municipais de Curitiba. Dissertação Programa de Pós-Graduação em Educação Setor de Educação da Universidade Federal do Rio Grande: Curitiba. 